\title{
The Characteristics of Nitinol in Spinal Implant Manufacturing
}

\author{
Mahdis Parsafar ${ }^{1}$, Sayed Khatiboleslam Sadrnezhaad ${ }^{2,{ }^{*}}$ and Nahid Hassanzadeh Nemati ${ }^{1}$ \\ ${ }^{1}$ Department of Biomedical Engineering, Science and Research Branch, Islamic Azad University, Tehran, Iran \\ ${ }^{2}$ Department of Materials Science and Engineering, Sharif University of Technology, Tehran, Iran \\ "Corresponding author: Department of Materials Science and Engineering, Sharif University of Technology, Tehran, Iran. Email: sadrnezh@yahoo.com
}

Received 2021 August 20; Revised 2021 December 11; Accepted 2022 January 05.

\begin{abstract}
Due to the increasing number of diseases related to the spine, we expect to see more research on the implants used in this area. These implants should have features such as strength, fatigue resistance, chemical stability and biocompatibility, which fortunately are seen in an alloy called nitinol. In this study, six lumbar vertebral implants were made of nitinol and these samples been studied by some experiments such as: X-ray diffraction and biocompatibility (evaluation of cytotoxicity by MTT assay). Finally, we came to the conclusion that the mentioned alloy with suitable microstructure is appropriate for medical applications specially as an orthopedic implant. According to the X-ray diffraction pattern, the samples have austenitic structures in the room temperature and the predominant phase of the porous sample is B2-NiTi. Since the sample should be biocompatible after placement in the body and should not cause an immune system reaction, this test was also examined and the samples were tested in vitro with an MTT kit and the biocompatibility was assessed. The results of biocompatibility tests also indicate the suitability of the implant in terms of cellular characteristics. These properties have made this alloy superior to other alloys in orthopedic implant utilization, especially in areas under continuous loading. It is hoped that the construction of this type of implant will pave the way for facilitating the treatment of spinal abnormalities.
\end{abstract}

Keywords: NiTi, Biocompatibility, Spinal Implant, Cytotoxicity

\section{Background}

Back pain is a serious problem for all ages, especially the elderly. Years of life disability (DALY) due to back pain and neck pain had an increase rate of 59\% from 1990 to 2015 (1) which relates to excessive stress and incorrect living habits (2-4). Asthe spine is a complex system consisting of vertebrae and cartilage that protects the spinal cord, remedies of back pain is expensive and difficult (4). In cases where non-invasive methods have not been successful, surgical methods such as disc replacement and vertebral ligation are recommended (5-8). Over the last 5 decades, orthopedic metal equipment has been used to correct the shape of the spine in scoliosis $(6,9-12)$. Orthopedic implants are mainly made of metal alloys that have shown good mechanical properties in the mentioned area (11). Stainless steel has also been used to repair the spine for a long time $(10,12)$. Recently, nitinol has attracted more attention due to its unique properties $(13,14)$.

Despite the good strength of metals, their young's modulus is higher than that of bone, which in turn causes the stress shielding phenomenon, which is problematic. The Young's modulus of natural bone is about $0.5-20$, nitinol 30 - 50, stainless steel 200 and cobalt-chromium- molybdenum alloy $240 \mathrm{GPa}$ (15-17). In a study, nitinol was compared with Co-Cr and Ti alloy, in which Nitinol showes 100 times better wear resistance than Ti alloy (18). On the other hand, due to its special properties, nitinol has various applications in both industry and medicine. Including: angiography, angioplasty, orthopedics, orthodontics, urology, guide wire and neurosurgery $(19,20)$. Noting the properties of NiTi, including its shape memory property due to the transformation of the martensite phase, and its super elasticity and biocompatibility properties, which made this alloy a suitable candidate for medical application (19). In another study in 2016 (20), the properties of thermo elastic and pseudo elasticity and shape memory of nitinol were stated. As mentioned, studies have shown that nitinol is one of the best choices for implants, especially in the neck and lumbar region (21). However, no immune stimulation was seen after nitinol placement. Therefore, it is a safe choice for implants (13).

So far, no research has been done on the use of nitinol alloy as a lumbar vertebral implant according to the patient's anatomy with the characteristics considered by the researchers of this project, so this study is completely original. Also, the techniques of making through sintering and weaving, while being simple and cost-effective, are com- 
pletely new for producing such a piece.

Studies comparing porous nitinol and solid nitinol showed that porous nitinol has better bone formation, osteocunductivity and bioactivity than mass nitinol (22). So in this study we also used porosity. In the construction of orthopedic implants, the point that should be considered is the phenomenon of tension shield. Because orthopedic implants are generally made of metals and their alloys, metals also usually have a high modulus of elasticity and when placed in the body may lead to the phenomenon of tension shields. Therefore, to prevent this problem, the alloy modulus should be reduced, which is possible by creating porosity.

\section{Objectives}

In this study, to reduce the modulus of elasticity, the part must be porous, which can be done with a $3 \mathrm{D}$ printer and the addition of porous materials with high accuracy. And we hope to be able to design and provide a metal implant for the lumbar vertebrae that provides some of the special properties (including shock absorption, good mechanical properties) in the vertebral region that have been part of orthopedic medical engineering vacuums. This study will help orthopedic medicine.

\section{Methods}

In this study, after preparing nickel and titanium hydride powders with a purity of $99.5 \%$ and $99.9 \%$ and a particle size of 10 microns and less than 50 microns, respectively, purchased from Merck Germany, the powders were combined with urea to create porosity. 50\% was mixed and then pressed with a press of $150 \mathrm{MPa}$, then the furnace was heated with argon atmosphere at $1050^{\circ} \mathrm{C}$ for 2 hours to sintering. It is worth mentioning that the exit of the atmosphere was done at a temperature of 200 degrees and 1 hour and also the decomposition of titanium hydride was done at a temperature of 500 degrees for 1 hour. Six sample with a diameter of $5 \mathrm{~mm}$ and a height of $7 \mathrm{~mm}$ was then obtained (Figure 1).

Also, for better patterning and tangibility of the implant, a plastic lumber vertebra was made by 3D printer method (Figure 2). Figure 2 was merely a mock-up made to better understand and feel the lumbar vertebrae.

The microstructure of the samples was examined by XRD. Since the sample should be biocompatible after placement in the body and should not cause an immune system reaction and degrade to adjacent tissue, this case was also examined and the samples were tested in vitro with an MTT kit and the biocompatibility was assessed.

\subsection{Description of Experiments}

Samples of lumbar vertebral implants made by sintering method were subjected to the following tests:

\subsubsection{Investigation of Alloy Microstructure}

XRD analysis (Seisert PTS3003) was used to ensure the alloying process and to study the fuzzy structure of the alloy. Under the situation of $\operatorname{CuK} \alpha$ radiation and $\lambda=1.54$. Scanning speed of 0.05 degrees per minute at an angular distance of 5 to 100 was selected.

\subsubsection{Biocompatibility Review}

In the next part, the sample was placed in contact with bone cells and the survival rate of the cells was evaluated and presented with MTT kit. The method is as follows: first, cells prepared in bulk in RPMI-1640 medium containing 50 units of penicillin and 50 micrograms of streptomycin per ml of culture medium supplemented with $10 \%$ of fetal calf serum in a culture flask in an incubator at $37^{\circ} \mathrm{C}$ and $5 \%$ carbon dioxide were cultured with $85 \%$ humidity. After 3 to 4 days (cell layer formation), the cells are removed from the surface of the flask by trypsin (0.25\%) and a suspension with a concentration of $4 \times 10^{4}$ cells per $\mathrm{ml}$ is prepared for use. On the other hand, the sample was sterilized by an oven (dry heat). The samples were placed in a container of 12 cells (each sample separately in a cell) and one cell without a sample is considered as a control. After placing the samples in each house, $2 \mathrm{~mL}$ of cell suspension is poured and placed in an incubator. The MTT solution is then added to the wells and incubated again. (For the preparation of MTT solution at a concentration of $5 \mathrm{mg} / \mathrm{mL}$, the amount of $50 \mathrm{mg}$ of MTT powder is dissolved in $10 \mathrm{mg}$ of $0.15 \mathrm{PBS}$ molar. After 3 to 5 hours of incubation at $5^{\circ} \mathrm{C}$, the cell supernatant is removed and instead $1 \mu \mathrm{L}$ of isopropanol solution (Merck, Germany) is added to the relevant cavities. In this way, the corresponding plate chambers are placed on the shaker for 1 to 4 minutes. Their contents are then read by a microtiter in $2 \mathrm{~nm}$. As seen, nitinol was biocompatible and good cell growth was seen from the sample.

\section{Results}

\subsection{Result of Alloy Microstructure}

XRD images of porous nitinol samples are given. As can be seen in Figure 3, the predominant phase of the porous sample is B2-NiTi, and Ni3Ti and NiTi2 sediments are also present in the field.

The following reactions occur during the ejaculation process:

$$
\begin{aligned}
& \text { 1. } \mathrm{Ni}+\mathrm{TiH}_{2} \rightarrow \mathrm{NiTi}+\mathrm{H}_{2}+\mathrm{Q} \\
& \text { 2. } \mathrm{Ni}+\mathrm{TiH}_{2} \rightarrow \mathrm{NiTi}_{2}+\mathrm{H}_{2}+\mathrm{Q} \\
& \text { 3. } \mathrm{Ni}+\mathrm{TiH}_{2} \rightarrow \mathrm{Ni}_{3} \mathrm{Ti}+\mathrm{H}_{2}+\mathrm{Q}
\end{aligned}
$$




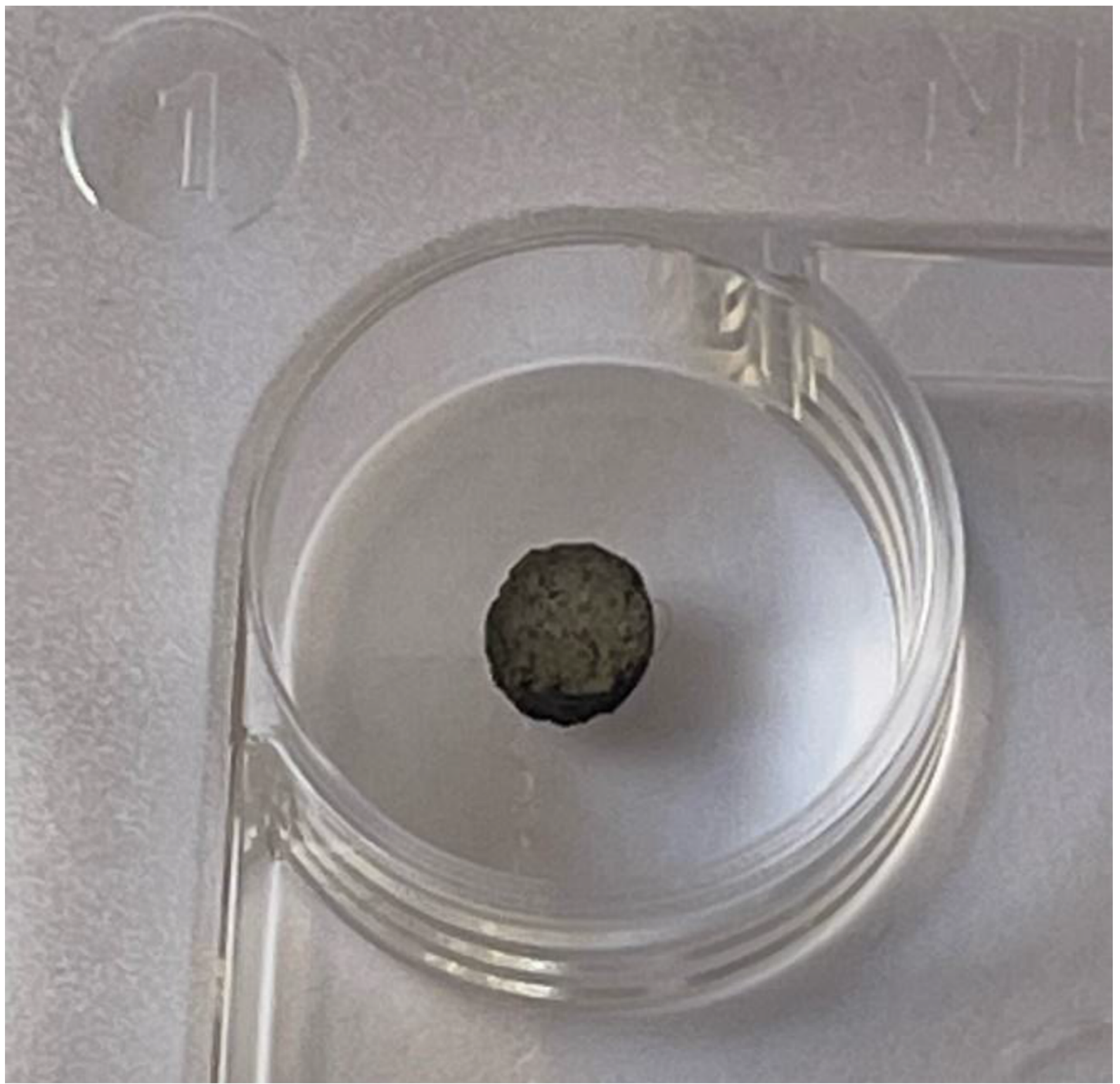

Figure 1. Sintered sample

According to the Ni-Ti fuzzy diagram, $\mathrm{Ni}_{3} \mathrm{Ti}$ and $\mathrm{NiTi}_{2}$ sediments are stable compounds in the Ni-Ti binary system. The second and third tier reactions are thermodynamically more stable. As a result, it is difficult to prevent the formation of these sediments in the excavation process and they are usually seen in the structure of the excavated parts. The sample is also porous and porosity reduces the penetration of nickel and titanium. This increases the titanium and nickel-rich areas and the formation of sediments in these areas. According to the X-ray diffraction pattern, the sample has an austenitic structure. Increasing the percentage of nickel reduces the start temperature of the martensite phase $(16,23)$. Therefore, at ambient temperature, the samples have an austenitic structure.

\subsection{Review of Biocompatibility Results}

MTT test was performed on two samples (Figure 4). The graph shows the number of cells in terms of time of one day and two days. By examining the diagram and comparing cell viability on nitinol samples and controls, it can be concluded that the nitinol sample is slightly toxic and cell 


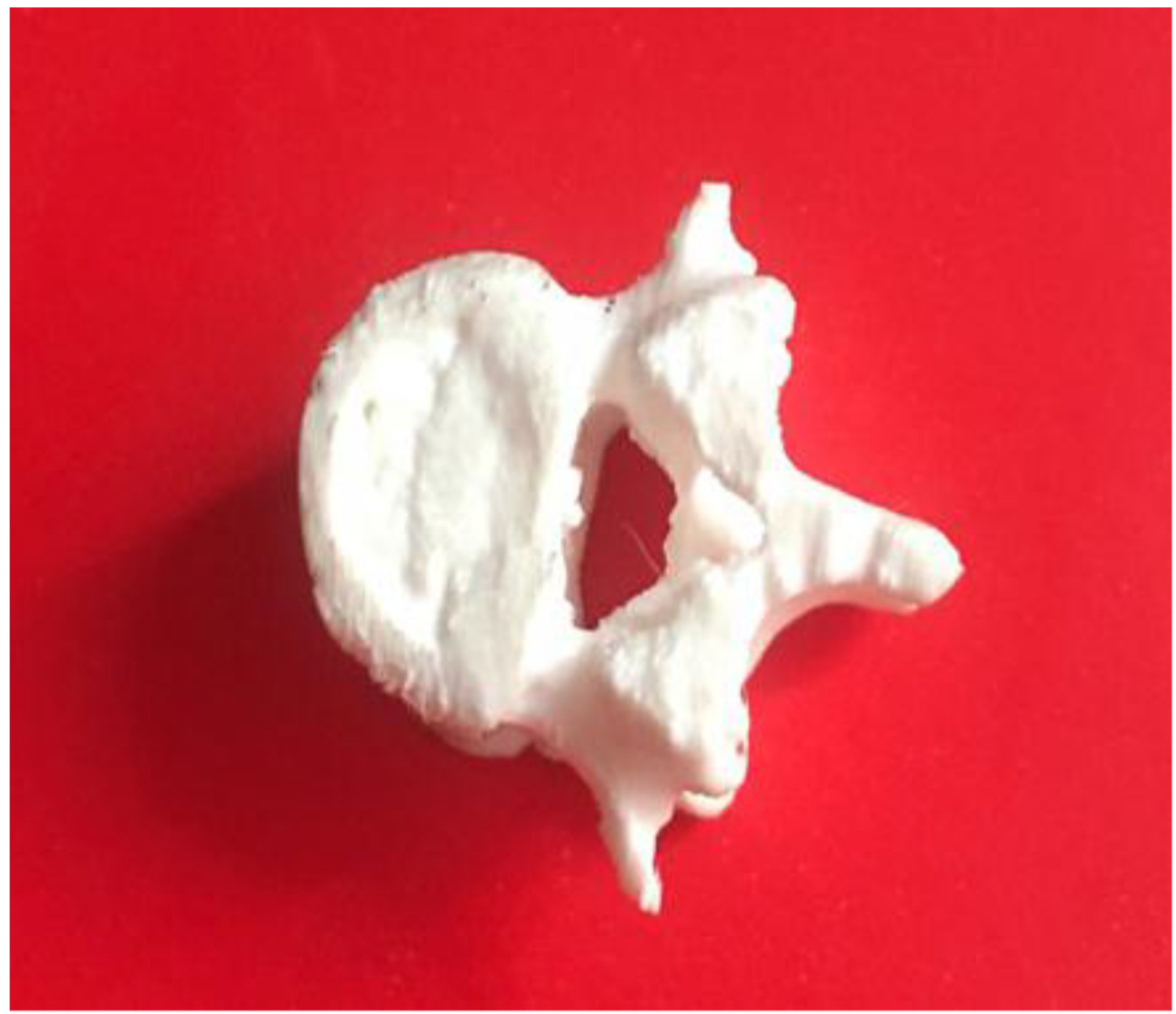

Figure 2.3D printed polymeric implant

viability is good and appropriate, and has not caused cell death.

\section{Discussion}

According to the X-ray diffraction pattern, the sample has an austenitic structure. This is due to the oxidation of the titanium on the surface and the enrichment of the samples with nickel. Increasing the percentage of nickel reduces the starting temperature of the martensite phase, so at ambient temperature the samples have an austenitic structure. Above the austenite finishing temperature is the cubic nitinol structure B2. Below this temperature are rhombohedral, tetragonal, orthorhombic and monoclinic
(24-27). Meanwhile, Ni-rich NiTi has unique memory properties due to $\mathrm{BCC} /$ rhombohedral structural changes (16, 28).

MTT test and cytotoxicity test showed good cell adhesion, which has various causes and many variables are involved (29). These properties have made this alloy superior to other alloys in orthopedic implant applications, especially in areas under continuous loading.

\subsection{Conclusion}

In this study, according to the experiments, it can be concluded that NiTi alloy can be suitable for being used as a material in implant manufacturing specially in spinal region. It is hoped that in the future we will work on different implant designs for orthopedic applications. 


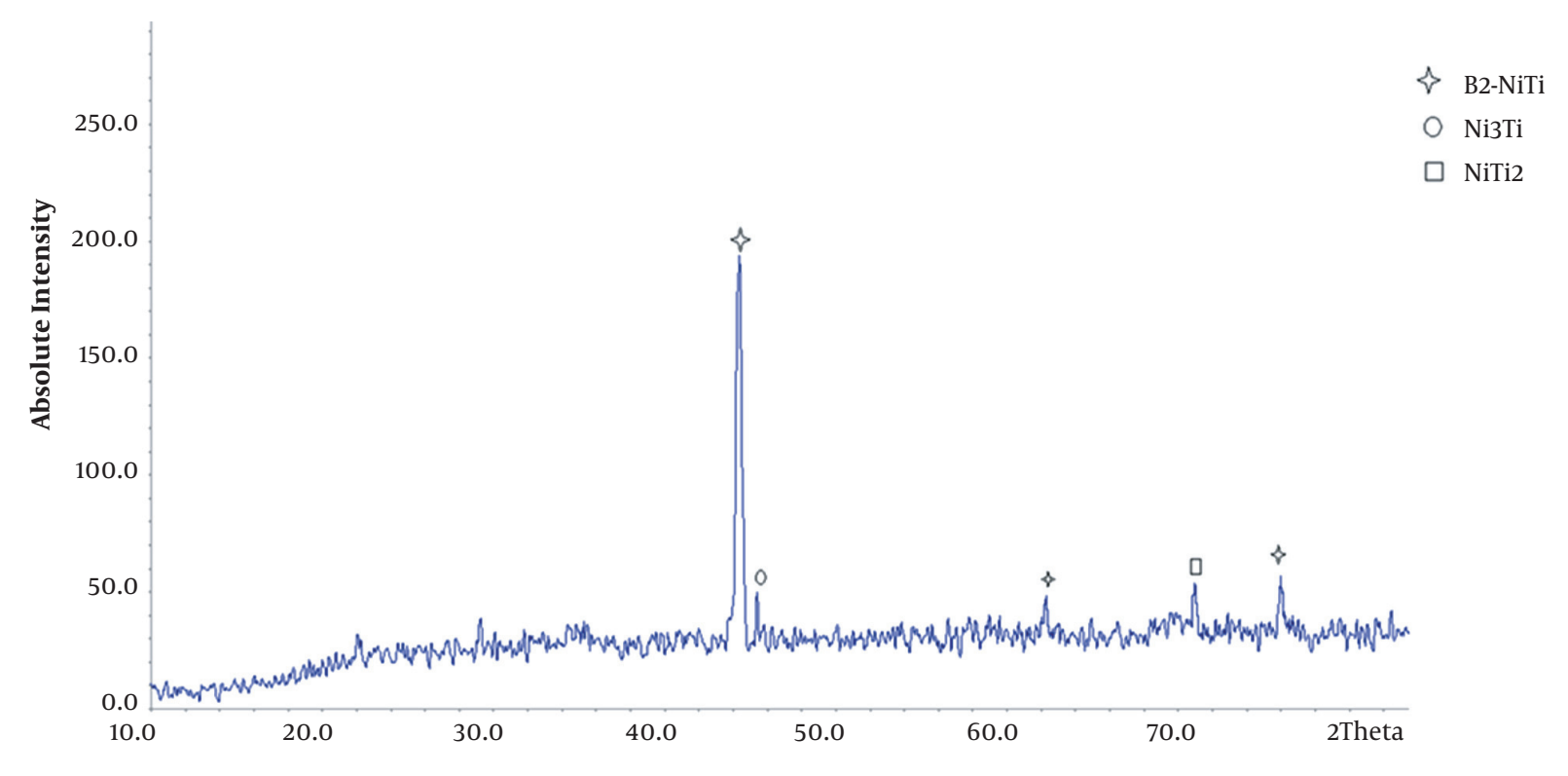

Figure 3. XRD pattern of the sample

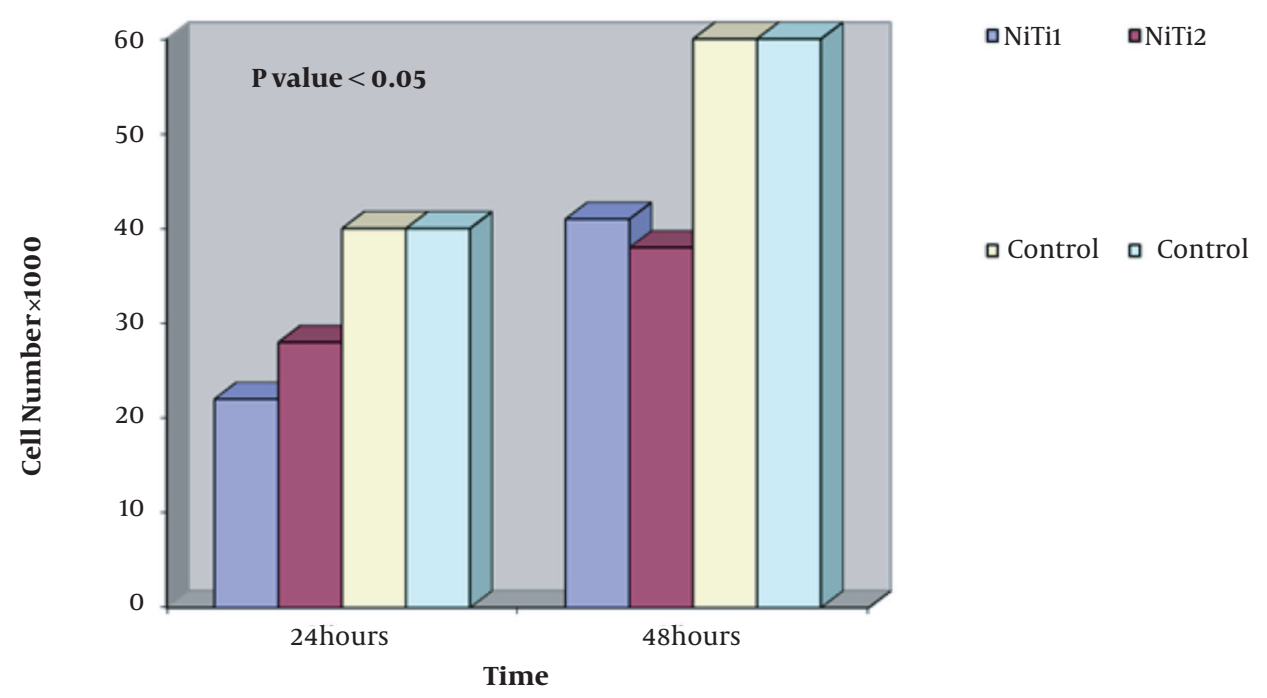

Figure 4. MTT test results for two samples

\section{Footnotes}

Authors' Contribution: Study concept and design, M.P, SK.S, N.H; Acquisition of data, M.P; Analysis and interpretation of data, M.P, SK.S; Drafting of the manuscript, M.P; Critical revision of the manuscript for important intellectual content, N.H, SK.S; Statistical analysis, M.P, SK.S; Administrative, technical, and material support, SK.S, M.P; Study supervision, SK.S, N.H.
Conflict of Interests: It was not declared by the author. Funding/Support: There is no funding/support.

\section{References}

1. Hurwitz EL, Randhawa K, Yu H, Cote P, Haldeman S. The Global Spine Care Initiative: A summary of the global burden of low back and neck pain studies. Eur Spine J. 2018;27(Suppl 6):796-801. doi: 10.1007/s00586-017-5432-9. [PubMed: 29480409]. 
2. Sanchez-Riera L, Wilson N, Kamalaraj N, Nolla JM, Kok C, Li Y, et al. Osteoporosis and fragility fractures. Best Pract Res Clin Rheumatol. 2010;24(6):793-810. doi: 10.1016/j.berh.2010.10.003. [PubMed: 21665127].

3. Anselmetti GC, Manca A, Marcia S, Chiara G, Marini S, Baroud G, et al. Vertebral augmentation with nitinol endoprosthesis: clinical experience in 40 patients with 1-year follow-up. Cardiovasc Intervent Radiol. 2014;37(1):193-202. doi: 10.1007/s00270-013-0623-1. [PubMed: 23652416].

4. Wolman DN, Heit JJ. Recent advances in Vertebral Augmentation for the treatment of Vertebral body compression fractures. Curr Phys Med Rehabil Rep. 2017;5(4):161-74. doi: 10.1007/s40141-017-0162-9.

5. Kamanli A, Karaca-Acet G, Kaya A, Koc M, Yildirim H. Conventional physical therapy with lumbar traction; clinical evaluation and magnetic resonance imaging for lumbar disc herniation. Bratisl Lek Listy. 2010;111(10):541-4. [PubMed: 21125798].

6. Morozova NS, Kolbovsky DA, Kazmin AI, Kolesov SV. The Use of Nitinol Rods in Surgical Treatment of Degenerative Scoliosis. 2.5Year Follow-Up. Coluna/Columna. 2016;15(1):22-5. doi: 10.1590/s1808185120161501156149.

7. Serra T, Capelli C, Toumpaniari R, Orriss IR, Leong JJ, Dalgarno K, et al. Design and fabrication of 3D-printed anatomically shaped lumbar cage for intervertebral disc (IVD) degeneration treatment. Biofabrication. 2016;8(3):35001. doi: 10.1088/1758-5090/8/3/035001. [PubMed: 27431399].

8. Taheri Andani M, Anderson W, Elahinia M. Design, modeling and experimental evaluation of a minimally invasive cage for spinal fusion surgery utilizing superelastic Nitinol hinges. J Intell Mater Syst Struct. 2014;26(6):631-8. doi: 10.1177/1045389x14541499.

9. Yoshihara $\mathrm{H}$. Rods in spinal surgery: A review of the literature. Spine J. 2013;13(10):1350-8. doi: 10.1016/j.spinee.2013.04.022. [PubMed: 23773430].

10. Kok D, Donk RD, Wapstra FH, Veldhuizen AG. The memory metal minimal access cage: a new concept in lumbar interbody fusion-a prospective, noncomparative study to evaluate the safety and performance. Adv Orthop. 2012;2012:898606. doi: 10.1155/2012/898606. [PubMed: 22567409]. [PubMed Central: PMC3332066].

11. Kok D, Grevitt M, Wapstra F, Veldhuizen A. The Memory Metal Spinal System in a Posterior Lumbar Interbody Fusion (PLIF) Procedure: A Prospective, Non-Comparative Study to Evaluate the Safety and Performance. Open Orthop J. 2012;6:220-5. doi: 10.2174/1874325001206010220. [PubMed: 22754599]. [PubMed Central: PMC3386510].

12. Kok D, Firkins PJ, Wapstra FH, Veldhuizen AG. A new lumbar posterior fixation system, the memory metal spinal system: an invitro mechanical evaluation. BMC Musculoskelet Disord. 2013;14:269. doi: 10.1186/1471-2474-14-269. [PubMed: 24047109]. [PubMed Central: PMC3871762].

13. Tahal D, Madhavan K, Chieng LO, Ghobrial GM, Wang MY. Metals in Spine. World Neurosurg. 2017;100:619-27. doi: 10.1016/j.wneu.2016.12.105. [PubMed: 28057595].

14. Chen B, Zheng YH, Zheng T, Sun CH, Lu J, Cao P, et al. The implantation of a Nickel-Titanium shape memory alloy ameliorates vertebral body compression fractures: a cadaveric study. Int J Clin Exp Med. 2015;8(9):16899-906. [PubMed: 26629241]. [PubMed Central: PMC4659129].

15. Wang X, Xu S, Zhou S, Xu W, Leary M, Choong P, et al. Topological design and additive manufacturing of porous metals for bone scaffolds and orthopaedic implants: A review. Biomaterials. 2016;83:127-41. doi: 10.1016/j.biomaterials.2016.01.012. [PubMed: 26773669].

16. Hosseini SA, Sadrnezhaad SK, Ekrami A. Phase transformation behavior of porous NiTi alloy fabricated by powder metallurgical method. Mater Sci Eng C. 2009;29(7):2203-7. doi:10.1016/j.msec.2009.05.006.

17. Kaya M, Çakmak Ö, Gülenç B, Atlı KC. Thermomechanical cyclic stability of porous NiTi shape memory alloy. Mater Res Bull. 2017;95:243-7. doi: 10.1016/j.materresbull.2017.07.016.

18. Lukina E, Kollerov M, Meswania J, Wertheim D, Mason P, Wagstaff $\mathrm{P}$, et al. Analysis of retrieved growth guidance sliding LSZ $4 \mathrm{D}$ devices for early onset scoliosis and investigation of the use of nitinol rods for this system. Spine. 2015;40(1):17-24. doi: 10.1097/BRS.0000000000000660. [PubMed: 25341983].

19. Wadood A. Brief Overview on Nitinol as Biomaterial. Adv Mater Sci Eng. 2016;2016:1-9. doi: 10.1155/2016/4173138.

20. Xenos-Despina S, Gregory N. The unique properties, manufacturing processes and applications of near equatomic Ni-Ti alloys. Shape Memory Superelasticity, DOI. 2016;10.

21. Zuev IV, Shchedrenok VV, Orlov SV, Zakhmatova TV, Moguchaya OV, Sebelev KI, et al. [The experience of dynamic fixation with nitinol implants for degenerative diseases of the spine]. Genij Ortop. 2014;(2). Russian.

22. Zhu SL, Yang XJ, Chen MF, Li CY, Cui ZD. Effect of porous NiTi alloy on bone formation: A comparative investigation with bulk NiTi alloy for 15 weeks in vivo. Mater Sci Eng C. 2008;28(8):1271-5. doi: 10.1016/j.msec.2007.11.010.

23. Zhu SL, Yang XJ, Fu DH, Zhang LY, Li CY, Cui ZD. Stress-strain behavior of porous NiTi alloys prepared by powders sintering. Mater Sci Eng A. 2005;408(1-2):264-8. doi: 10.1016/j.msea.2005.08.012.

24. Sadrnezhaad SK, Katiraei S, Ghasemi A. Intermetallic phase formation during combustion synthesis of mechanically activated Ni-Ti alloy. ADMT J. 2014;7(4).

25. Sanjabi S, Cao YZ, Sadrnezhaad SK, Barber ZH. Binary and ternary NiTi-based shape memory films deposited by simultaneous sputter deposition from elemental targets. J Vac Sci Technol A: Vac Surf Film. 2005;23(5):1425-9. doi: 10.1116/1.2011404.

26. Mehrpouya M, Gisario A, Elahinia M. Laser welding of NiTi shape memory alloy: A review. J Manuf Process. 2018;31:162-86. doi: 10.1016/j.jmapro.2017.11.011.

27. Sadrnezhaad SK, Raz SB. Effect of Microstructure on Rolling Behavior of NiTi Memory Alloy. Mater Manuf Process. 2008;23(7):646-50. doi: 10.1080/10426910802316526.

28. Sadrnezhaad SK, Parsafar M, Rashtiani Y, Jadidi M. Nitinol Spinal Vertebrae: A Favorable New Substitute. Int J Eng. 2019;32(6). doi: 10.5829/ije.2019.32.06c.07.

29. Sevcikova J, Pavkova Goldbergova M. Biocompatibility of NiTi alloys in the cell behaviour. Biometals. 2017;30(2):163-9. doi: 10.1007/s10534017-0002-5. [PubMed: 28190193]. 